Gynecologic and

Obstetric Investigation
Gynecol Obstet Invest 2011;71:77-86

DOI: $\underline{10.1159 / 000320736}$
Received: September 23, 2009

Accepted after revision: March 28, 2010

Published online: December 9, 2010

\title{
Altered Gene Expression Profile in Vaginal Polypoid Endometriosis Resembles Peritoneal Endometriosis and Is Consistent with Increased Local Estrogen Production
}

\author{
S.M. Syrcle ${ }^{a} \quad$ K.E. Pelch ${ }^{a} \quad$ A.L. Schroder ${ }^{a} \quad$ B.M. Nichols ${ }^{a}$ M.P. Mills ${ }^{a} \quad$ B.F. Barrier ${ }^{a}$ \\ A.D. Havey ${ }^{b}$ S.C. Nagel ${ }^{a}$
}

Departments of a Obstetrics, Gynecology and Women's Health, and ${ }^{\mathrm{b}}$ Anatomical and Pathological Sciences,

University of Missouri School of Medicine, Columbia, Mo., USA

\section{Key Words}

Endometriosis, vaginal polypoid · Polyps, vaginal/cervical · Gene expression

\section{Abstract}

Background: In a university hospital setting, a 25-year-old woman presented with large vaginal and cervical polyps. Past medical history was significant for stage IV endometriosis. Polypectomy was performed and the polyps were histologically consistent with endometriosis. Gene expression was compared with control vaginal tissue to assess if the altered gene expression profile was similar to peritoneal endometriosis. Methods and Results: Using quantitative reverse transcription, real-time $P C R$, estrogen receptor- $\beta$ expression was found to be upregulated 10 -fold while estrogen receptor- $\alpha$ expression was downregulated 5 -fold in the vaginal polyp relative to control vaginal tissue. The estrogen-synthesizing enzyme aromatase was upregulated 8-fold and $3 \beta$ hydroxysteroid dehydrogenase was upregulated 400 -fold in the polyp. Immunohistochemical staining revealed altered cell type localization for progesterone receptor in the polyp and increased cell proliferation in polyp stromal cells relative to control. Conclusions: Increased proliferation in the vaginal polypoid endometriotic tissue may be due to increased local estrogen production. The altered gene expression profile was very similar to the altered gene expression profile seen in peritoneal endometriosis.

Copyright $\odot 2010$ S. Karger AG, Base

\section{Introduction}

Endometriosis is an estrogen-dependent disease defined by the presence of endometrial glands and stroma outside of the uterus, typically in the pelvic cavity [1]. It is one of the most common benign gynecologic diseases, occurring in up to $10 \%$ of women [2]. However, vaginal endometriosis is a rare presentation of endometriosis, occurring in $<3 \%$ of endometriosis cases [3]. The most common location of vaginal endometriosis is within the posterior vaginal fornix [3]. Parker et al. [4] described 24 cases of vaginal polypoid endometriosis, each with multiple polypoid lesions.

The etiology of endometriosis remains poorly understood. While retrograde menstruation places shed endo-

\section{KARGER}

(๑) 2010 S. Karger AG, Basel

Fax +4161306 1234

E-Mail karger@karger.ch

www.karger.com
Accessible online at: www.karger.com/goi
Susan C. Nagel, PhD

Department of Obstetrics, Gynecology and Women's Health, University of Missour DC051.00, M659 MSB, 1 Hospital Drive

Columbia, MO 65212 (USA)

Tel. +1 573884 3028, Fax +1 573882 9010, E-Mail nagels@ health.missouri.edu 


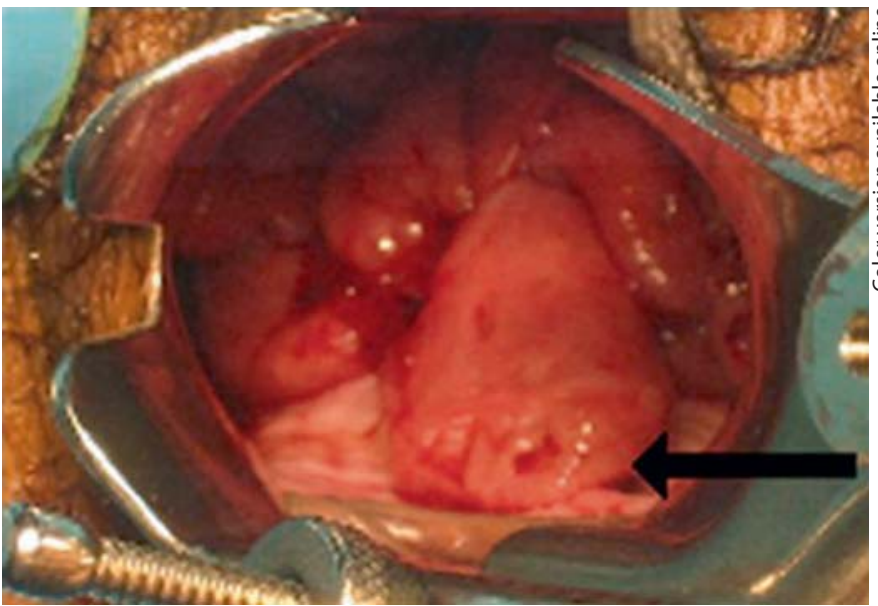

Fig. 1. Vaginal polyps at the time of surgery. The majority of these large polyps protruded from the vaginal mucosa of the posterior fornix as a 'beard-like' linear array. Notice the ulceration at the tip of the largest polyp (arrow).

metrial tissue in the peritoneal cavity of most women, this tissue implants and grows only in a small portion of women. Whether this results from an impaired immune system and/or altered eutopic endometrium is unclear. In an attempt to elucidate the etiology of peritoneal endometriosis, several genes have been identified to have altered expression in ectopic endometriotic tissue. Expression-profiling studies have been conducted to characterize the altered gene expression profile in endometriotic tissue [5-7]. Many genes that appear dysregulated in ectopic tissue involve steroid hormone receptors and enzymes involved in steroid hormone biosynthesis and metabolism $[8,9]$. Overexpression of estrogen-synthesizing enzymes has been reported, which has led to the hypothesis of an increased local estrogenic milieu in peritoneal endometriosis [9]. Consistent with this hypothesis, many estrogen-regulated genes are also altered in peritoneal endometriotic tissue [9].

To our knowledge, there are no reports of a systematic evaluation of altered gene expression in vaginal polypoid endometriosis. We describe a patient with multiple reproductive tract pathologies, including polypoid masses in the cervix and vagina, and stage IV endometriosis. We aimed to determine gene expression patterns in the vaginal polyps relative to control vaginal tissue to elucidate the potential mechanisms of altered cell growth, particularly genes involved with steroid hormone synthesis and/ or signaling, since these genes are known to be altered in peritoneal endometriotic tissue.

\section{Case Report}

In January 2007, a 25-year-old nulliparous, African-American woman presented to her primary provider with a history of dysmenorrhea, dyspareunia, and chronic pelvic pain. The patient reported dysmenorrhea since menarche. She experienced continuous bleeding independent of menstruation for 4 months before presentation that was severe enough to cause symptomatic anemia. She had had dyspareunia chronically for 6 years before presentation and post-coital bleeding for 8 months before presentation. She was unable to have coitus for 4 months before presentation because of large friable vaginal polyps protruding just past her hymen.

Surgical history was significant for laparoscopy in $2001 \mathrm{sec}-$ ondary to pelvic pain and laparotomy in 2005 to remove large bilateral endometriomata. Also noted at surgery were complete obliteration of the cul-de-sac and extensive adhesions throughout the pelvis that included the large bowel, small bowel and omentum. At the time of presentation to our clinic, her medications included Depo-Provera, iron and a multivitamin. She had been placed on Depo-Provera 4 months prior to presentation in an attempt to control the continuous vaginal bleeding.

On physical exam, separation of the labia revealed soft tissue finger-like projections that extended $1 \mathrm{~cm}$ past the hymen. On speculum exam, a number of large polypoid masses were noted in the vaginal vault. Bleeding and patient discomfort limited the exam. The patient was then scheduled for examination under anesthesia with indicated procedures to diagnose and treat this condition.

Pelvic examination, vaginal polypectomy, endocervical curettage, uterine endometrial curettage, and hysteroscopy were performed under general anesthesia. During this exam, 6 discreet vaginal polyps were noted to arise from the posterior vaginal fornix and continue along the entire length of the fornix right to left (fig. 1). Each measured approximately $0.5-1.0 \mathrm{~cm}$ in diameter and $2-5 \mathrm{~cm}$ in length. They formed a 'beard-like' array arising from below the cervix and were highly vascularized with a significant amount of bleeding with minimal disturbance. In addition, 3 discreet cervical polyps measuring $0.25 \mathrm{~cm}$ in diameter and $1.0-2.5$ $\mathrm{cm}$ in length were noted. All polyps were excised. Dilatation and curettage was performed. Hysteroscopy was performed and the uterine cavity was noted to have an anomalous intrauterine contour, resembling the 'T-shaped uterus' described in some women with in utero exposure to the synthetic estrogen diethylstilbestrol (DES).

\section{Methods}

Vaginal Polyp and Control Vaginal Tissue

This study was approved by the University of Missouri Health Sciences Institutional Review Board. Prior to polypectomy surgery, the patient was informed that her case was unique and offered the opportunity for a portion of discarded tissue to be collected and frozen for research use. At the patient's direction, one surgically removed $3.5 \times 1.0 \mathrm{~cm}$ vaginal polyp was transected and a $1.6 \times 1.0 \mathrm{~cm}$ portion was stored at $-80^{\circ} \mathrm{C}$ to be utilized for research purposes. A separate vaginal polyp was formalin-fixed and sent to pathology. Discarded vaginal tissue from 4 control patients undergoing vaginal repair surgery was obtained and im- 
Table 1. Patient and control characteristics

\begin{tabular}{llll}
\hline Subject & $\begin{array}{l}\text { Age } \\
\text { years }\end{array}$ & Menopausal status & Modifications/hormonal status \\
\hline Patient & 25 & Premenopausal & Depo-Provera \\
Control 1 & 42 & Premenopausal & None \\
Control 2 & 40 & Premenopausal & Combined OCPs/Paraguard IUD \\
Control 3 & 16 & Premenopausal & Combined OCPs \\
Control 4 & 53 & Postmenopausal & Premarin, local vaginal cream \\
\hline
\end{tabular}

Table 2. Primers used for real-time PCR

\begin{tabular}{|c|c|c|c|c|c|}
\hline $\begin{array}{l}\text { Gene } \\
\text { name }\end{array}$ & Accession No. & Forward primer & Reverse primer & $\begin{array}{l}\text { Efficiency } \\
\%\end{array}$ & $\begin{array}{l}\text { Primer } \\
\mathrm{nm}\end{array}$ \\
\hline$A R$ & NM_001011645 & GGACTTTGTACAGGGAACCAGGGA & GCAGGTCTTCTGGGGTGGAAAGTA & 98.1 & 200 \\
\hline EGFR & NM_005228 & CGGGCTCTGGAGGAAAAGAAAGTT & CCCAAGGACCACCTCACAGTTATTG & 99.6 & 200 \\
\hline ESR1 & NM_000125 & CAGCATGAAGTGCAAGAACGTGG & GCCTCCCCCGTGATGTAATACTTTT & 92.0 & 70 \\
\hline ESR2 & NM_001437 & TGGGCACCTTTCTCCTTTAGTGGT & TGAGCATCCCTCTTTGAACCTGGA & 107.3 & 200 \\
\hline GAPDH & NM_002046 & AAGGCTGGGGCTCATTTGCA & TGCAGGAGGCATTGCTGATGAT & 83.4 & 200 \\
\hline$H S D 17 B 1$ & NM_000413 & GTGGGAGGATTGATGGGGCTG & CCCAAAGGGCAGCAGCAGAA & 111.0 & 100 \\
\hline$H S D 17 B 8$ & NM_014234 & CAGGTGCCTGCTGGAACAAGTG & TGCCCTTGAGGTTGACAGCTATGA & 90.9 & 200 \\
\hline$H S D 3 B 1$ & NM_000862 & CAGAACAAGACCAAGCTGACAGTGC & TGATACAGGCGGTGTGGATGATG & 97.5 & 200 \\
\hline LTF & NM_002343 & AGACTCCCCCATCCAGTGTATCCA & TGTCTTTCGGTCCCGTAGACTTCC & 96.5 & 200 \\
\hline PTGES & NM_004878 & ACGTGGAACGCTGCCTCAGG & CAGGAAGTGCATCCAGGCGAC & 99.7 & 100 \\
\hline PTGES2 & NM_025072 & CCTTCCTCGACTTCCATGCCC & TTGCGAGCTTTCTCCTTCCTGG & 98.2 & 100 \\
\hline
\end{tabular}

mediately placed in RNA Later (Ambion, Austin, Tex., USA) or formalin. Controls had no history of endometriosis. Patient and controls were de-identified. Characteristics of these patients are summarized in table 1 . Control patients were selected with different hormonal milieus to compare gene expression in the vaginal polyp to normal vaginal tissue under different hormonal conditions.

\section{RNA Isolation and cDNA Synthesis}

The vaginal polyp tissue, stored at $-80^{\circ} \mathrm{C}$, was further broken up into small segments in liquid nitrogen. Six of these segments were placed in RNA Later-Ice (Ambion) $24 \mathrm{~h}$ prior to RNA isolation. Polyp tissue and control vaginal tissue were blotted to remove RNA Later-Ice and RNA Later solution, respectively, and immediately homogenized in Lysis-Binding Solution (Ambion). Total RNA was extracted using RNAqueous (Ambion) and DNAsed with TURBO-DNA free (Ambion) according to the manufacturer's protocol. Quantity of total RNA was determined using a NanoDrop 3.0.1 spectrophotometer (Coleman Technologies, Wilmington, Del., USA). RNA isolated from control patient 3 was found to be degraded on agarose gel electrophoresis and was not used for gene expression. For the vaginal polyp and control samples 1, 2 and 4, cDNA was synthesized from 250 ng total RNA per reaction with Superscript III Platinum RT (Invitrogen, Carlsbad, Calif., USA) according to the manufacturer's instructions.

\section{Primer Design and Real-Time PCR}

Primer sets (table 2) were designed using Vector NTI (Invitrogen). The primers were chosen to amplify short PCR products of less than 200 base pairs, to have a GC content of $40-60 \%$, an annealing temperature of $55-60^{\circ} \mathrm{C}$, and a $\Delta \mathrm{G}$ of less than -8 . Primer sequences, concentrations and efficiencies (E) used are summarized in table 2. Primer set efficiencies were determined for all primer pairs prior to use by triplicate runs of four serial 10 -fold dilutions of cDNA using the equation: $\mathrm{E}=10^{[-1 / \text { slope] }}[10]$. Gel electrophoresis and melting curve analyses were performed to confirm amplicon specificity. PCRs were performed in the ABI 7500 sequence detector using Platinum SYBR-Green PCR reagents (Invitrogen) according to the manufacturer's instructions, except that a $25-\mu l$ reaction volume was used. PCR amplification was performed in duplicate from cDNA and from a mock cDNA reaction without reverse transcriptase (noRT) under the following conditions: $2 \mathrm{~min}$ at $50^{\circ} \mathrm{C}, 2 \mathrm{~min}$ at $95^{\circ} \mathrm{C}$, followed by a total of 40 cycles of $15 \mathrm{~s}$ at $95^{\circ} \mathrm{C}$ and $32 \mathrm{~s}$ at $60^{\circ} \mathrm{C}$. Either no amplification was seen in the noRT reactions or the amplification was at least seven cycles different from the reverse transcription reactions.

\section{Calculation of Relative Gene Expression}

Each real-time PCR for all genes was repeated independently 3 times. Fold change in gene expression was calculated relative to 

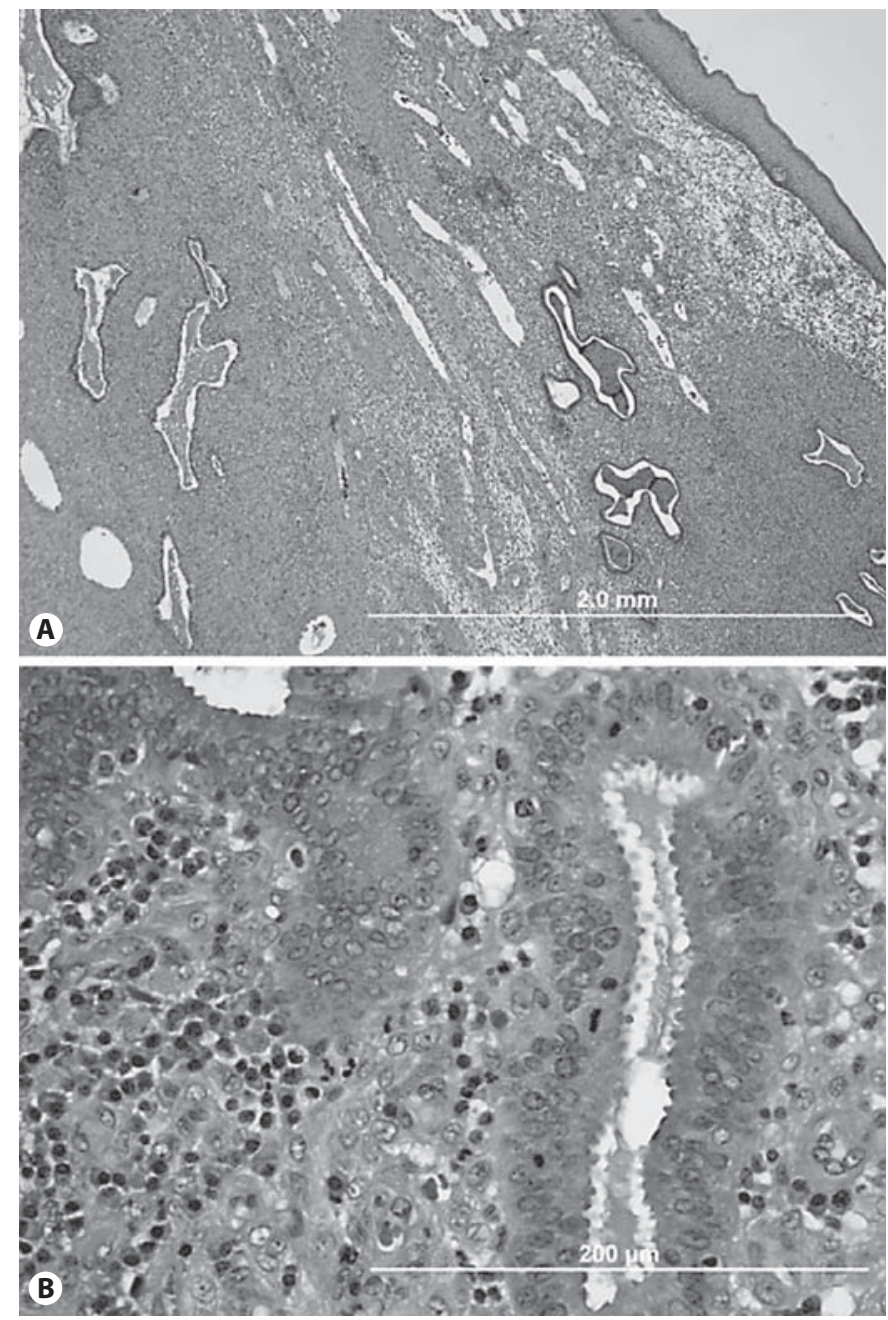

Fig. 2. Representative HE section of vaginal polyp at $\times 40(\mathbf{A})$ and $\times 400$ magnification (B). Vaginal polyp surfaced by squamous mucosa, composed of predominantly tubular glands within a markedly inflamed and decidualized stroma. Some glands were lined by columnar cells with pseudostratification with mitotic activity.

control 1 based on the efficiency corrected $\Delta$ Ct method [10]. Thus, fold change $=1$ means gene expression was not different from control patient 1. Expression of glyceraldehyde-3-phosphate dehydrogenase (GAPDH) was not different between the patient and controls and was used as the reference housekeeping gene.

\section{Histochemistry}

One vaginal polyp and pieces of control vaginal tissues were formalin fixed for $24 \mathrm{~h}$, washed 3 times with PBS, dehydrated, paraffin-embedded and hematoxylin and eosin (HE) stained by the University of Missouri Pathology Lab or Research Animal Diagnostic Laboratory histology (RADIL; University of Missouri), respectively. Histological analysis was performed by pathologist Dr. Ann Havey at the University of Missouri.

\section{Immunohistochemistry}

University of Missouri RADIL histology cut 5- $\mu \mathrm{m}$ sections of all tissues and performed immunohistochemistry (IHC) for progesterone receptor (PR) and Ki67. Antigen retrieval was performed by incubating slides at $95^{\circ} \mathrm{C}$ for $20 \mathrm{~min}$ in Antigen Retrieval Solution pH 6.0 (Dako No. S1699, Carpentaria, Calif., USA). Slides were allowed to cool for $20 \mathrm{~min}$ and were then washed three times in water. Immunoperoxidase staining was performed for the PR using rabbit polyclonal anti-human antibody diluted 1:50 (Dako, No. A0098, immunogen was a synthetic peptide from the DNA-binding domain, amino acids 533-547, so this antibody binds all PR isoforms) and the cell proliferation marker Ki67 using rabbit polyclonal anti-human antibody diluted 1:200 (Labvision No. RB-1510, Fremont, Calif., USA). The secondary antibodies were biotinylated swine anti-rabbit reagents. For IHC quantification, the analysis was blinded with respect to tissue source. Positively stained cells were manually counted using Metamorph software in four separate fields at $\times 400$ magnification, and the average of positive cells per field \pm standard deviation was calculated. Although the tissue of subject 3 could not be used for realtime PCR analysis because of RNA degradation, it could be used for IHC because separate tissue was collected for this purpose.

\section{Statistics}

Analyses are presented as mean \pm standard deviation for 3 independent real-time PCR assays. Quantitative statistics could not be performed as all controls are unique regarding their hormone status. Thus, descriptive statistics are presented.

\section{Results}

\section{Serum Hormone Levels}

Serum hormone levels were measured approximately 2 weeks after surgery in the patient. Thyroid-stimulating hormone and free thyroxine were both in the normal range at 2.55 and $0.85 \mu \mathrm{g} / \mathrm{dl}$, respectively. Progesterone was suppressed at $0.5 \mathrm{ng} / \mathrm{ml}$ and estradiol $\left(\mathrm{E}_{2}\right)$ was in the low normal range at $27 \mathrm{pg} / \mathrm{ml}$. Progesterone and $\mathrm{E}_{2}$ were low, presumably due to negative feedback from the patient's use of Depo-Provera. The patient's hematocrit was $30 \%$.

\section{Patient and Control Characteristics (table 1)}

The patient and controls 1-3 were premenopausal women aged 16-42 years. All women, except control 1, were using some form of exogenous hormone therapy. Control 4 was postmenopausal and using a vaginal estrogen cream. Control 3 had vaginal repair surgery secondary to a rectovaginal fistula after parturition.

\section{Histology}

Histological description of the vaginal polyp was consistent with vaginal polypoid endometriosis (fig. 2). The vaginal polyp was surfaced by squamous mucosa with 

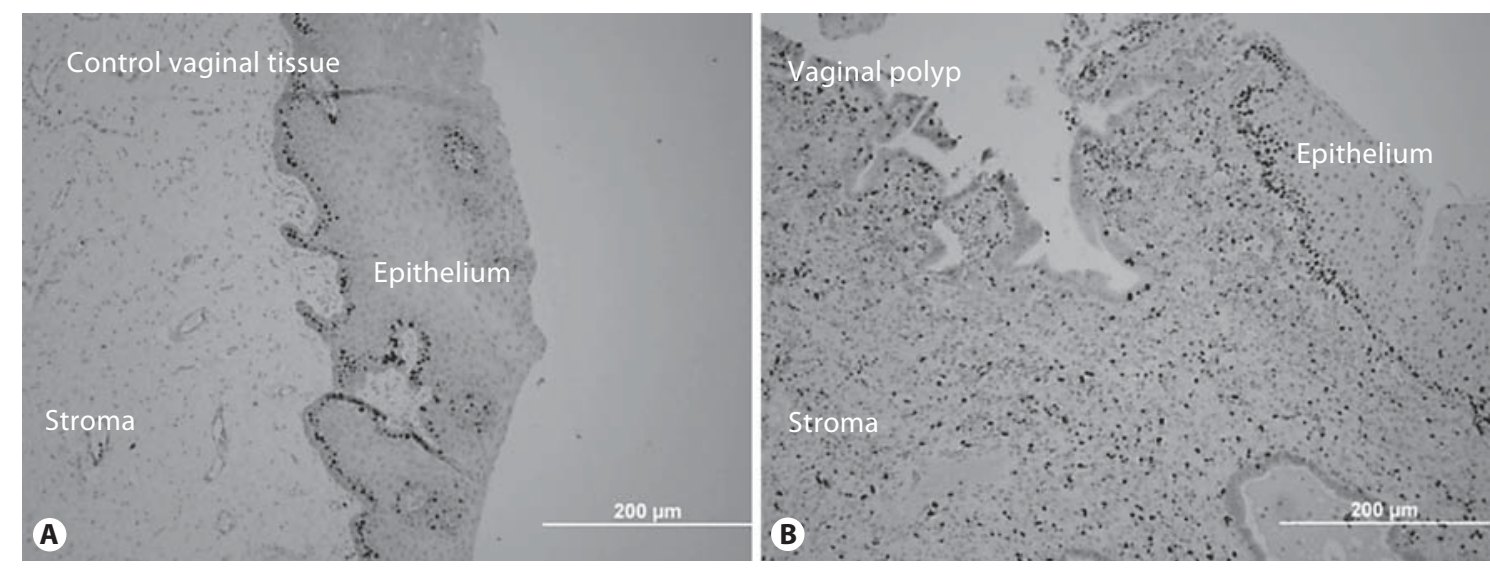

Fig. 3. Increased cell proliferation in vaginal polyp stromal cells relative to control. Ki67 immunohistochemical staining of control (A) and vaginal polyp (B). There are abundant Ki67-positive cells in the polyp stroma and a lack of positive cells in the control stromal cells. $\times 200$.

extensive surface ulceration and underlying acute and chronic inflammation. Interspersed within the markedly decidualized stroma (consistent with the patient's use of Depo-Provera) were predominantly tubular glands, some of which were lined by pseudostratified columnar epithelium with mitotic activity, which is consistent with endometrial gland morphology (fig. 2). Focal tubal and mucinous metaplasia was identified, with some glands showing mild dilation and intraluminal mucin. Foci of stromal hemorrhage and scattered hemosiderin-laden macrophages were also seen, which is characteristic of endometriosis. Thus, we conclude that the vaginal polyp contained endometriosis. The cervical polyps were reported as benign polypoid fragments of squamocolumnar epithelium with acute and chronic inflammation.

\section{Cell Proliferation}

A dramatic upregulation of cell proliferation was seen in the stromal cells of the vaginal polyp relative to control vaginal stromal cells (fig. 3). In the vaginal polyp stroma, there were on average 50 times more Ki67-positive immunostained cells per field $(\times 400$; fig. $4 \mathrm{~A})$ than in control stromal cells. Similar numbers of proliferative cells were present in the epithelium of the vaginal polyp and controls (fig. 3, 4).

\section{Progesterone Receptor Immunolocalization}

The number of progesterone receptor (PRA + PRB)positive cells in the polyp stroma was 2.5 - to 5 -fold greater than the number of PR-positive cells in the control stroma (fig. 4B). The number of PR-positive epithelial cells varied among all specimens examined (fig. 4B).

\section{Expression of Genes for Steroid and Growth Factor Receptors}

Real-time PCR was used to measure gene expression in vaginal polyp tissue versus control vaginal tissue (fig. 5). Estrogen receptor- $\alpha$ (ESR1) expression was 5-fold lower in the polyp relative to premenopausal controls 1 and 2, and showed similar expression as control 4 , a postmenopausal woman using a vaginal estrogen cream (fig. 5A). Estrogen receptor- $\beta$ (ESR2) expression was higher in the vaginal polyp than in control tissue: 9-fold relative to controls 1 and 2, and 60-fold relative to control 4 (fig. 5B). The expression of androgen receptor, epidermal growth factor and G-protein-coupled receptor 30 (putative membrane estrogen receptor) did not differ between the vaginal polyp and controls.

\section{Expression of Genes Involved in Steroid Synthesis}

The expression of enzymes involved in steroid synthesis was altered in the vaginal polyp relative to controls (fig. 5C, D). Expression of the primary estrogen-synthesizing enzyme, cytochrome P450, family 19 , subfamily a, polypeptide 1 (CYP19A1), which converts testosterone to $\mathrm{E}_{2}$, was upregulated 9-, 14- and 30-fold relative to controls 1,2 and 4, respectively. Expression of $3 \beta$-hydroxysteroid dehydrogenase (HSD3B1), an enzyme controlling one of the first steps in steroid hormone biosynthesis, was elevated over 400 -fold in the vaginal polyp relative to controls. The expression of $17 \beta$-hydroxysteroid dehydrogenase $(H S D 17 B) 8$, an enzyme that converts $E_{2}$ to $E_{1}$ (estrone), was downregulated 2 - and 3 -fold relative to premenopausal controls 1 and 2, respectively. The expression of $H S D 17 B 1$, an enzyme that converts $E_{1}$ to $E_{2}$, 

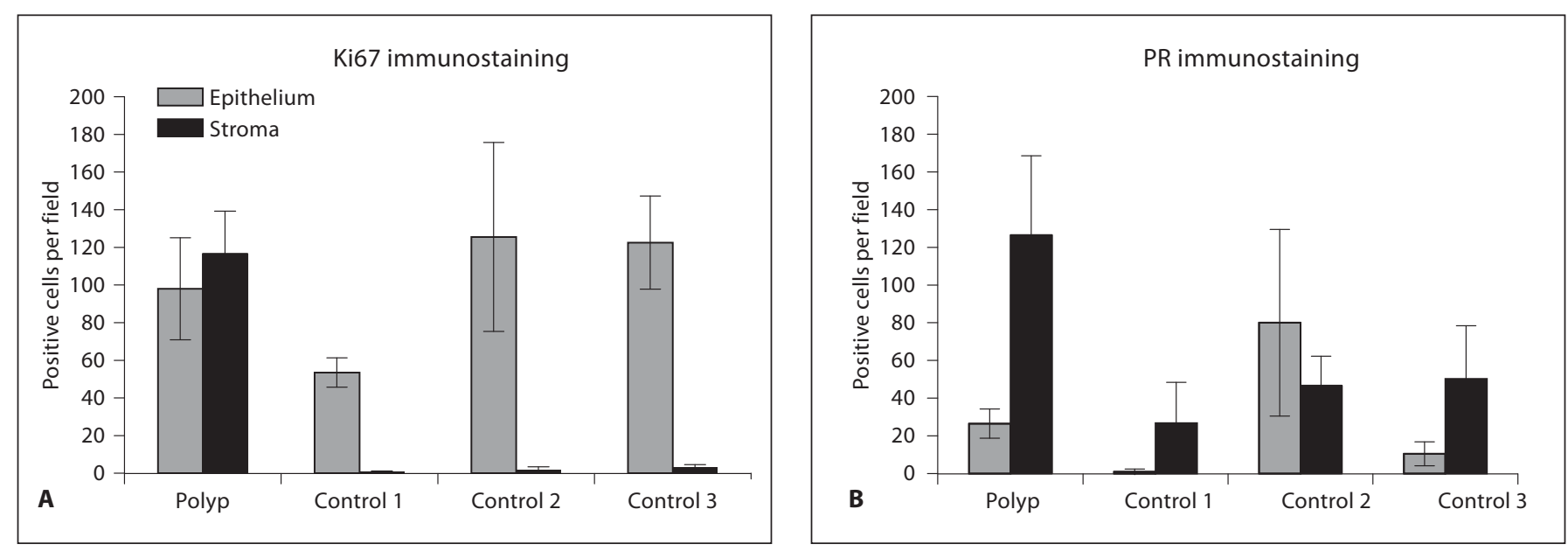

Fig. 4. Quantification of the number of $\operatorname{Ki67}(\mathbf{A})$ and progesterone receptor $(\mathbf{B})$ positive cells per field $(\times 400$ magnification). Positive cells were counted in four fields per section and averaged. Error bars represent standard deviation.

Table 3. Altered gene expression in the vaginal polyp relative to normal vaginal tissue and previously reported estrogen-regulated gene expression

\begin{tabular}{llll}
\hline & $\begin{array}{l}\text { Expression } \\
\text { in polyp }\end{array}$ & $\begin{array}{l}\text { Estrogen } \\
\text { regulation }^{\mathrm{b}}\end{array}$ & $\begin{array}{l}\text { Reference } \\
\text { No. }\end{array}$ \\
\hline CYP19A1 & $\uparrow$ & $\uparrow$ & 5,8 \\
ESR1 & $\downarrow$ & $\downarrow$ & 16 \\
HOXA10 & $\downarrow$ & $\uparrow$ & 11 \\
HSD3B1 & $\uparrow$ & $\uparrow$ & 17 \\
KI67 & $\uparrow($ Stroma) & $\uparrow$ & 18 \\
LTF & $\uparrow$ & $\uparrow$ & 19 \\
PGR & $\uparrow($ Stroma) & $\uparrow$ & 20 \\
PTGES & $\uparrow$ & $\uparrow$ & 21 \\
\hline
\end{tabular}

a Arrows represent direction of gene expression change in vaginal polyp relative to control vaginal tissue in the current study.

${ }^{b}$ Arrows represent direction of gene expression change altered by estrogen in previous reports

remained unaltered. The expression of prostaglandin $\mathrm{E}$ synthase (PTGES) was upregulated greater than 2-fold relative to controls 1 and 2, and PTGES2 did not differ between samples.

\section{Expression of Estrogen-Regulated Genes}

The expression of lactoferrin (LTF) and homebox A10 (HOXA10) has been reported to be acutely regulated by estrogen [11, 12]. The expression of LTF and HOXA10 was altered in the vaginal polyp relative to control vaginal tis- sue (fig. 5E, F). LTF was dramatically elevated over 800 fold in the vaginal polyp relative to controls. HOXA10 gene expression was greater than 3 -fold lower in the vaginal polyp relative to controls.

The expression of other estrogen-regulated genes described above was consistent with increased local estrogen production (table 3): ESR1 was downregulated and CYP19A1 and HSD3B1 were upregulated. In addition, PGR and KI67 proteins were upregulated in polyp stromal tissue.

\section{Discussion}

This is the first report of gene expression in vaginal polypoid endometriotic tissue compared with control human vaginal tissue. We found altered expression of genes involved in steroid hormone synthesis and signaling. These results suggest that increased local estrogen production may have led to patient pathology. Overall, the gene expression profile is strikingly similar to that seen in peritoneal endometriosis.

\section{Altered Gene Expression in Estrogen Synthesis and Metabolism}

Several investigations have led to the hypothesis that the growth of endometriotic lesions is perpetuated by increased local estrogen production due to altered expression of estrogen-synthesizing enzymes [9]. HSD3B1 is an essential enzyme in the synthesis of estrogen precursors 

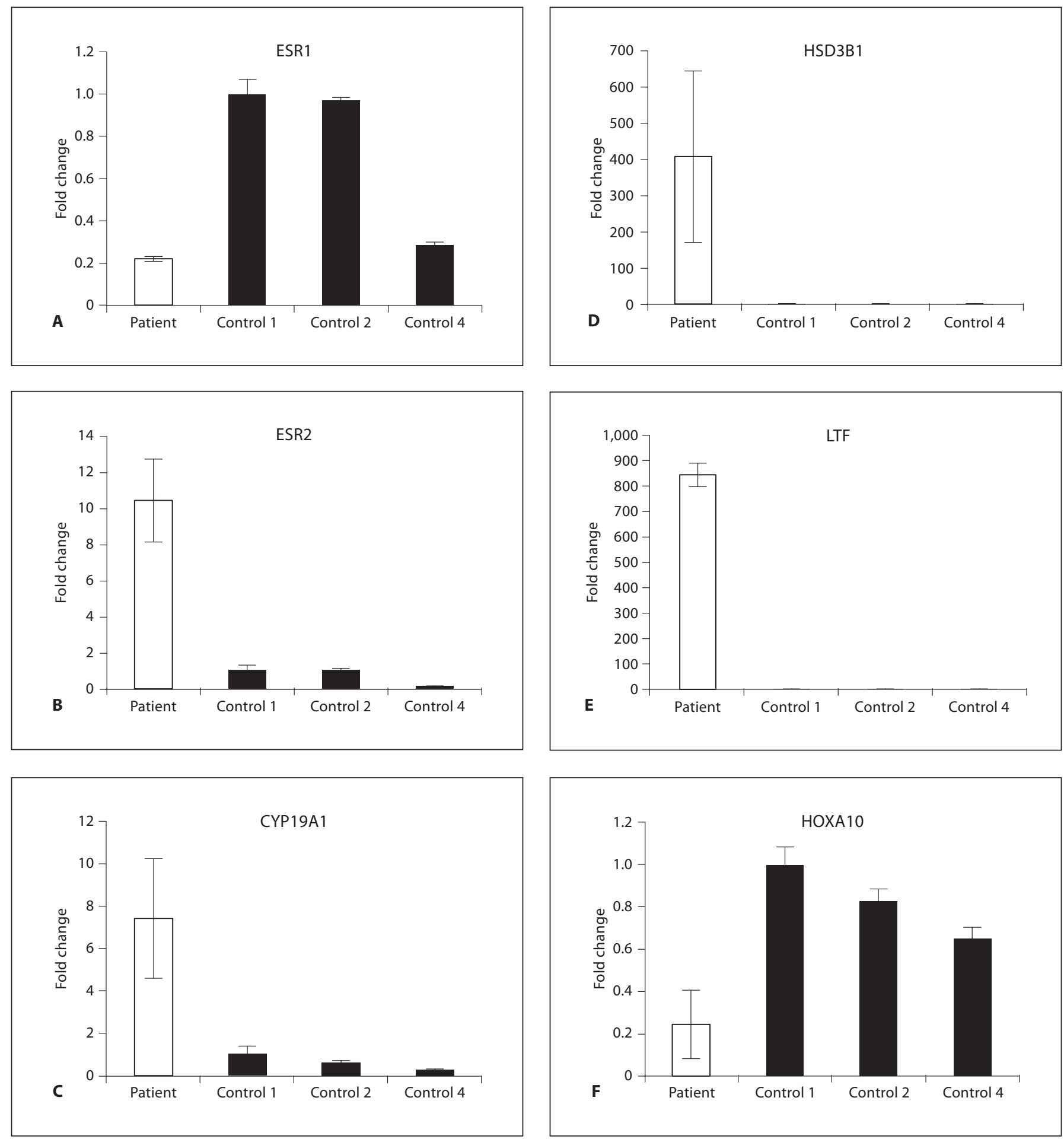

Fig. 5. Relative gene expression in vaginal tissue. Fold change of selected genes between vaginal polyp (patient) and controls 1 (reference), 2 and 4. RNA from control 3 was degraded and excluded from this analysis. Realtime PCR was performed and data were normalized to GAPDH using the Pfaffl method [10]. Each assay was repeated three times and the average fold change is shown. Error bars represent standard deviation. 
and has been reported to be overexpressed in endometriotic lesions [5]. Its expression was upregulated over 400fold in the vaginal polyp. PTGES is the final enzyme involved in prostaglandin (PG) E2 synthesis and it has been reported to be overexpressed in endometriotic lesions [13]. PTGES expression was upregulated in the vaginal polyp relative to control tissue. $P G E 2$ is a potent inducer of CYP19A1, the key estrogen-synthesizing enzyme that converts C19 androgens to estrogens. CYP19A1 overexpression has been reported in endometriotic lesions [9] and was upregulated about 8 -fold in the vaginal polyp relative to control tissue.

Overexpression of $H S D 17 B 1$ (which converts $\mathrm{E}_{1}$ to the more potent $\mathrm{E}_{2}$ ) has been reported in endometriotic tissue [9]. While its expression did not differ in control and polyp tissue in the current study, $H S D 17 B 1$ is largely expressed in epithelial cells [14], and its observed expression profile may be due to the increased stromal/epithelial cell ratio in the vaginal polyp. Expression of HSD17B8 was downregulated in the polypoid tissue similar to reports of HSD17B2 expression in endometriotic tissue. Both enzymes convert $\mathrm{E}_{2}$ to the less potent $\mathrm{E}_{1}[9,15]$. In the current study, we found increased expression of estrogensynthesizing genes and decreased expression of estrogenmetabolizing genes in the vaginal polyp relative to control vaginal tissue.

\section{Estrogen-Regulated Gene Expression}

Increased expression of $H S D 3 B$ and aromatase (CYP19A1) suggest an increase in local estrogen production. The gene expression profile in this vaginal polyp largely reflects an environment of increased local estrogen synthesis. In the present study, eight genes have previously been reported to be estrogen-responsive (table 3 ). The altered gene expression profile was consistent with known estrogen gene regulation for 7 of 8 of these genes $[5,8,16-21]$. HOXA10 was the only gene that differed; however, the downregulation of HOXA10 is consistent with its downregulation in peritoneal endometriosis [5, 22]. The most dramatic difference in gene expression occurred in the LTF gene. Expression was greater than 800 fold higher in the vaginal polyp than in control vaginal tissue (fig. 5). LTF expression is acutely regulated by estrogen and is a known immunomodulator that is upregulated in response to inflammatory stimuli [23].

Estrogens are known to stimulate endometrial cell proliferation. In the current study, we found increased proliferation in the vaginal polyp stroma relative to control vaginal tissue consistent with estrogen-regulated cell proliferation. This is despite the patient's use of the long-
Table 4. Altered gene expression profile in vaginal polyp relative to normal vaginal tissue and previously reported gene expression profile in peritoneal endometriosis

\begin{tabular}{llll}
\hline & $\begin{array}{l}\text { Expression in } \\
\text { polyp }^{\text {a }}\end{array}$ & $\begin{array}{l}\text { Peritoneal } \\
\text { endometriosis }\end{array}$ & $\begin{array}{l}\text { Refer- } \\
\text { ence No. }\end{array}$ \\
\hline CYP19A1 & $\uparrow$ & $\uparrow$ & $8-10$ \\
ESR1 & $\downarrow$ & $\downarrow$ & $8,9,11$ \\
ESR2 & $\uparrow$ & $\uparrow$ & $8,9,11$ \\
HOXA10 & $\downarrow$ & $\downarrow$ & 8,12 \\
HSD17B1 & - & $\uparrow$ & 5 \\
HSD3B1 & $\uparrow$ & $\uparrow$ & 5 \\
LTF & $\uparrow$ & $\uparrow$ & 5 \\
$P G R$ & $\uparrow$ & $\downarrow$ & 5 \\
$P T G E S$ & $\uparrow$ & $\uparrow$ & 8,13 \\
\hline
\end{tabular}

a Arrows represent direction of gene expression change in vaginal polyp relative to control vaginal tissue in the current study.

$\mathrm{b}$ Arrows represent direction of gene expression change in peritoneal endometriotic tissue relative to endometrium in previous reports.

acting progestin, Depo-Provera, which may suggest failure of normal progesterone inhibition of estrogen-stimulated proliferation, which has been hypothesized for peritoneal endometriosis $[24,25]$. Whether the vaginal polyp arose because of local estrogen production cannot be ascertained in the present study, however, its continued growth was likely promoted by increased local estrogen production.

\section{Altered Gene Expression of Estrogen Receptors}

Xue et al. [26] have reported the hypomethylation and overexpression of ESR2 in endometriotic tissue. Bukulmez et al. [8] report that the ESR2/ESR1 ratio is increased in endometriotic tissue. In the current study, ESR2 expression was upregulated while ESR1 was downregulated. The ESR2/ESR1 ratio was increased 50- to 100-fold in the vaginal polyp relative to control vaginal tissue. This is similar to the altered ratio reported by Bukulmez et al. [8] in peritoneal endometriotic lesions.

\section{Gene Expression Profile in Polyp Is Similar to That in}

\section{Peritoneal Endometriotic Tissue}

In women with endometriosis, many genes have been reported to be dysregulated. This gene expression profile was largely observed in the vaginal polyp relative to control vaginal tissue. In the present study, expression of 7 of 9 genes showed a similar profile between polypoid and 
peritoneal endometriosis (table 4). The genes that differed were $H S D 17 B 1$ and $P R$. Expression of $H S D 17 B 1$ was unchanged in the current study, whereas its expression has been reported to be upregulated in endometriotic tissue relative to endometrium [9]. As discussed earlier, this may be due to the greatly increased stromal/epithelial cell ratio in the vaginal polyp. $P R$ expression has been reported to be downregulated in endometriotic tissue relative to endometrium $[5,27]$. In the current study, PR protein expression was upregulated in polyp stromal cells relative to control vaginal tissue. Increased PR expression may have resulted from the patients use of Depo-Provera, as progestins have been reported to increase expression of $P R$ in endometrial stromal cells [20]. On the whole, the altered gene expression profile in this vaginal polyp relative to control vaginal tissue was similar to the altered gene expression profile reported for endometriotic lesions versus endometrium.

\section{Limitations}

We report here the first description of altered gene expression in vaginal polypoid tissue relative to control vaginal tissue. While a limitation of the current study is the small number of samples, vaginal polyps are rare. Another limitation to the study is the variation in the hormonal milieu of study subjects. We were unable to locate a patient on Depo-Provera undergoing vaginal repair surgery in order to obtain a sample of control vaginal tissue. Lastly, we were unable to collect normal vaginal and endometrial tissue from the polyp patient due to lack of consent.

\section{Conclusion}

Even with these limitations, the altered gene expression profile seen in the vaginal polyp was remarkably similar to the altered gene expression profile in peritoneal endometriotic lesions. This, along with similar histological findings, led to the conclusion that the vaginal polyp is vaginal polypoid endometriosis. While the patient's peritoneal endometriosis and T-shaped uterus are consistent with developmental DES exposure [28, 29], this exposure is impossible to assess, as access to maternal history was severely limited, and a history of in utero exposure could be neither confirmed nor refuted. Of note, the patient was born 10 years after gestational use of DES was banned in the United States. We conclude that the proximate cause for the increased proliferation of these tissues is increased local estrogen production as a result of overexpression of HSD3B1 and CYP19A1, as hypothesized for peritoneal endometriosis [9].

\section{Acknowledgements}

The authors wish to thank Drs. Danny Schust and Kathy Sharpe-Timms for helpful suggestions. Funding was provided by the University of Missouri School of Medicine Summer Research Fellowship to S.M.S., the Endocrine Society to A.L.S, NIH No. 5T90DK070105 to K.E.P., and grants from the University of Missouri to S.C.N. and B.F.B., and March of Dimes Basil O'Connor Starter Award and NIH KO1 DK6056701 to S.C.N.

\section{References}

1 Hompes PG, Mijatovic V: Endometriosis: the way forward. Gynecol Endocrinol 2007;23: 5-12.

2 Vigano P, Parazzini F, Somigliana E, Vercellini P: Endometriosis: epidemiology and aetiological factors. Best Pract Res 2004;18: 177-200.

- 3 Azzena A, Ferrara A, Castellan L, Quintieri F, Salmaso R: Vaginal endometriosis. Two case reports and review of the literature on rare urogenital sites. Clin Exp Obstet Gynecol 1996;23:94-98.

4 Parker RL, Dadmanesh F, Young RH, Clement PB: Polypoid endometriosis: a clinicopathologic analysis of 24 cases and a review of the literature. Am J Surg Pathol 2004;28:285-297.

-5 Borghese B, Mondon F, Noël JC, Fayt I, Mignot TM, Vaiman D, et al: Gene expression profile for ectopic versus eutopic endometrium provides new insights into endometriosis oncogenic potential. Mol Endocrinol 2008;22:2557-2562.
6 Eyster KM, Klinkova O, Kennedy V, Hansen KA: Whole genome deoxyribonucleic acid microarray analysis of gene expression in ectopic versus eutopic endometrium. Fertil Steril 2007;88:1505-1533.

$\checkmark 7$ Kao LC, Germeyer A, Tulac S, Lobo S, Yang JP, Taylor RN, et al: Expression profiling of endometrium from women with endometriosis reveals candidate genes for diseasebased implantation failure and infertility. Endocrinology 2003; 144:2870-2881.

$\checkmark 8$ Bukulmez O, Hardy DB, Carr BR, Word RA, Mendelson CR: Inflammatory status influences aromatase and steroid receptor expression in endometriosis. Endocrinology 2008; 149:1190-1204.

-9 Bulun SE, Gurates B, Fang Z, Tamura M, Sebastian S, Zhou J, et al: Mechanisms of excessive estrogen formation in endometriosis. J Reprod Immunol 2002;55:21-33.
10 Pfaffl MW: A new mathematical model for relative quantification in realtime RT-PCR. Nucleic Acids Res 2001;29:e45.

11 Taylor HS, Arici A, Olive D, Igarashi P: HOXA10 is expressed in response to sex steroids at the time of implantation in the human endometrium. J Clin Invest 1998;101: 1379-1384.

12 Teng CT, Gladwell W, Beard C, Walmer D, Teng CS, Brenner R: Lactoferrin gene expression is estrogen responsive in human and rhesus monkey endometrium. Mol Hum Reprod 2002;8:58-67.

13 Chishima F, Hayakawa S, Yamamoto T, Sugitani M, Karasaki-Suzuki M, Sugita K, et al: Expression of inducible microsomal prostaglandin E synthase in local lesions of endometriosis patients. Am J Reprod Immunol 2007;57:218-226. 
14 Bulun SE, Zeitoun KM, Takayama K, Sasano $\mathrm{H}$ : Estrogen biosynthesis in endometriosis: molecular basis and clinical relevance. J Mol Endocrinol 2000;25:35-42.

-15 Villar J, Celay J, Alonso MM, Rotinen M, de Miguel C, Migliaccio M, et al: Transcriptional regulation of the human type 8 17beta-hydroxysteroid dehydrogenase gene by C/EBPbeta. J Steroid Biochem Mol Biol 2007;105: 131-139.

16 Dardes RC, Schafer JM, Pearce ST, Osipo C, Chen B, Jordan VC: Regulation of estrogen target genes and growth by selective estrogen-receptor modulators in endometrial cancer cells. Gynecol Oncol 2002;85:498506.

17 Chen YJ, Lee MT, Yao HC, Hsiao PW, Ke FC, Hwang JJ: Crucial role of estrogen receptoralpha interaction with transcription coregulators in follicle-stimulating hormone and transforming growth factor betal up-regulation of steroidogenesis in rat ovarian granulosa cells. Endocrinology 2008;149:46584668 .
18 Punyadeera C, Verbost P, Groothuis P: Oestrogen and progestin responses in human endometrium. J Steroid Biochem Mol Biol 2003;84:393-410.

19 Teng CT: Lactoferrin gene expression and regulation: an overview. Biochem Cell Biol 2002;80:7-16.

20 Tseng L, Zhu HH: Regulation of progesterone receptor messenger ribonucleic acid by progestin in human endometrial stromal cells. Biol Reprod 1997;57:1360-1366.

21 Frasor J, Weaver AE, Pradhan M, Mehta K: Synergistic up-regulation of prostaglandin E synthase expression in breast cancer cells by 17beta-estradiol and proinflammatory cytokines. Endocrinology 2008;149:6272-6279.

22 Browne H, Taylor H: HOXA10 expression in ectopic endometrial tissue. Fertil Steril 2006; 85:1386-1390.

23 Conneely OM: Antiinflammatory activities of lactoferrin. J Am Coll Nutr 2001;20:389S$397 \mathrm{~S}$.

24 Burney RO, Talbi S, Hamilton AE, Vo KC, Nyegaard M, Nezhat CR, et al: Gene expression analysis of endometrium reveals progesterone resistance and candidate susceptibility genes in women with endometriosis. Endocrinology 2007; 148:3814-3826.
25 Osteen KG, Bruner-Tran KL, Eisenberg E: Reduced progesterone action during endometrial maturation: a potential risk factor for the development of endometriosis. Fertil Steril 2005;83:529-537.

26 Xue Q, Lin Z, Cheng YH, Huang CC, Marsh E, Yin P, et al: Promoter methylation regulates estrogen receptor 2 in human endometrium and endometriosis. Biol Reprod 2007; 77:681-687.

-27 Attia GR, Zeitoun K, Edwards D, Johns A, Carr BR, Bulun SE: Progesterone receptor isoform A but not B is expressed in endometriosis. J Clin Endocrinol Metab 2000;85: 2897-2902.

28 Missmer SA, Hankinson SE, Spiegelman D, Barbieri RL, Michels KB, Hunter DJ: In utero exposures and the incidence of endometriosis. Fertil Steril 2004;82:1501-1508.

29 Swan SH: Intrauterine exposure to diethylstilbestrol: long-term effects in humans. APMIS 2000;108:793-804. 